\title{
Exploring the relationship between population mobility and HIV risk: evidence from Tanzania
}

Kevin D. Deane ${ }^{1}$, Penina Samwell Ngalya ${ }^{2}$, Lucas Boniface ${ }^{2}$, Grace Bulugu ${ }^{2}$ \& Mark Urassa $^{2}$

${ }^{1}$ Northampton Business School, University of Northampton

Northampton Business School

University of Northampton

Park Campus

Boughton Green Road

Northampton

NN2 7AL

United Kingdom

Phone: +44 (0) 1604893485

${ }^{2}$ National Institute of Medical Research, Tanzania

Mwanza Branch

Isamilo

Mwanza

Tanzania

E-mail for corresponding author: Kevin.Deane@northampton.ac.uk 


\begin{abstract}
Migration and population mobility has long been regarded as an important structural driver of HIV. Following initial concerns regarding the spatial spread of the disease, mobile populations are viewed to engage in higher levels of risky sexual behaviours than non-mobile groups. However, beyond the case studies of mineworkers and truck drivers, the statistical evidence is inconclusive, suggesting that the relationship between mobility and risk is not well understood. This study investigated how engaging in specific livelihoods that involve mobility influences sexual behaviour and HIV risk. A qualitative research project, including focus groups and in-depth interviews with key mobile groups, was conducted in Northern Tanzania. The findings show that the patterns and conditions of moving related to the requirements of each different economic activity influence the nature of relationships that mobile groups have whilst away, how and where local sexual networks are accessed, and the practicalities of having sex. This has further implications for condom use. Risk behaviours are also shaped by local sexual norms related to transactional sex, emphasising that the roles of mobility and gender are interrelated, overlapping, and difficult to disentangle.
\end{abstract}

Keywords

Mobility, Migration, HIV/AIDS, Structural Drivers, Transactional sex, 


\section{Introduction}

Although individualistic approaches to HIV prevention have dominated the policy and academic arena (Campbell \& Williams, 1999), it has long been acknowledged that social structures influence the dynamics of the epidemic (Hahn, 1991). More recently, a growing body of literature has (re) emphasised the role that structural/social factors play in shaping risk behaviours and risk contexts (Auerbach, Parkhurst, \& Caceres, 2011; Geeta Rao Gupta, Parkhurst, Ogden, Aggleton, \& Mahal, 2008; Sumartojo, Doll, Holtgrave, Gayle, \& Merson, 2000), with these concerns now integrated into the global policy agenda (UNAIDS, 2010).

One important structural driver of HIV is migration and/or population mobility. Whilst population mobility has played an important role in the historical spatial spread of the disease (Iliffe, 2006), linking geographically separate epidemics (Caldwell, Anarfi, \& Caldwell, 1997; Tanser, Lesueur, Solarsh, \& Wilkinson, 2000), current thinking within the health literature sees migrants as populations that are vulnerable to infection, engaging in higher levels of risky sexual behaviours than those who remain at home ( McGrath, Eaton, Newell and Hosegood 2015; Palk and Blower 2015; Schulyer et al., 2015). The standard narrative is that mobile individuals have sex while they are away from home for a range of reasons that include being separated temporarily from their spouses, and the enhanced opportunities for extra-marital sex that being away from home brings, and on return home transmit the virus to spouses or partners that have stayed behind (Deane, Johnston \& Parkhurst 2013; Weine \& Kashuba, 2012). Non-mobile spouses may also engage in sexual interactions whilst their partner is away, adding to the risk of infection (Lurie et al., 2003). Modelling exercises emphasise this concern, demonstrating that prevalence rates across the general population stabilise at a higher level in scenarios in which migration is accompanied by increasing levels of risky sexual behaviours than scenarios in which it is not (Coffee, Lurie, \& Garnett, 2007).

Two case studies, truck drivers and mineworkers (Baltazar et al., 2015; Campbell, 1997, 2003; Carswell, Lloyd, \& Howells, 1989; Douglas, 2000; Kamwanga, Simbaya, \& Luhana, 2006; Lurie et al., 2003a), dominate the literature on migration, mobility and HIV that focuses on sub-Saharan Africa. Although it remains unclear to what extent the lessons from these case studies can be extrapolated across all mobile populations, they are, with some exceptions (Thomas, Haour-Knipe, \& Aggleton, 2010) generally accepted. Beyond these well-known case studies, further investigation of the relationship between migration/mobility and HIV risk tests for statistically significant differences in HIV prevalence or sexual risk behaviours (or both) between 'non-mobile' and 'mobile' groups (Coffee et al., 2005; Khan et 
al., 2008; Kishamawe et al., 2006; Lagarde et al., 2003; Lydie et al., 2004; Mmbaga et al., 2008; Vissers et al., 2008). However, evidence from these studies is inconclusive, inconsistent, and in some cases contradictory, with no universal correlation between mobility and HIV risk for men or women (Deane, Parkhurst \& Johnston 2010). This is in part due to the limitations of the statistical framework used, with migration and population mobility reduced to an abstract individual variable, conflating many different forms of mobility. This approach is also unable to incorporate migration/mobility as dynamic socio-economic processes, and fails to address the importance of a range of factors such as who moves, why they move, where they go, why they go to specific places, the livelihood activities that are engaged in whilst away, and the practicalities of being away (Deane et al., 2010). Further, studies on truck drivers and mineworkers highlight that risky sexual behaviours are related to a range of factors, such as unsafe working and living conditions (Campbell, 1997; Kamwanga et al., 2006) that are not necessarily related to 'being away', challenging the standard narrative. A final concern is that statistical analyses fail to generate new policy conclusions beyond suggesting that mobile groups should be 'targeted' with standard prevention programmes such as behaviour change campaigns and STI treatment (Khan et al., 2008; Lagarde et al., 2003), or in some cases that couples should be encouraged to move together (Kishamawe et al., 2006). Therefore, whilst migration and mobility are strongly associated with the epidemic, this is a relationship that requires further unpacking.

This article presents findings from a qualitative research project conducted in northern Tanzania that explored the relationship between economic population mobility and HIV risk. The qualitative approach used in this research was chosen as both a complement and critique of the previous statistical approaches discussed here. In contrast to previous inter-disciplinary work on mobility and HIV that draws on a psycho-social framework (Campbell, 1997), this project utilised a materialist approach (Bernstein, 2010) that sought to understand how engaging in specific livelihoods that involve mobility, and the associated lifestyles this brings, influences sexual behaviour and HIV risk. This approach enabled the incorporation of mobility as a socio-economic process, whilst also capturing individual's experiences of engaging in these processes. The evidence presented below focuses on a comparative analysis of the experiences of mobile farmers and maize traders.

\section{Methods}


The study site for the fieldwork conducted in this project was a political ward in Magu district, Mwanza region, Tanzania, located around 20km outside of Mwanza city. The ward includes an urban centre situated around the main road, a peri-urban area surrounding the urban centre, with the remainder of the ward classified as rural (Boerma, Urassa, Senkoro, Klokke, \& Ngweshemi, 1999), and is increasingly under the sphere of influence of Mwanza city. The study site was chosen as it was the site of two previous statistical studies on mobility and HIV (Kishamawe et al., 2006; Vissers et al., 2008) that came to different conclusions (Deane et., al 2010), and also reported high levels of mobility, with $60 \%$ of men and $43 \%$ of women classified as mobile in the study by Kishamawe et al (2006). Sexual behaviours reported in these studies suggested that approximately $30 \%$ of the male population had a casual partner, and that around $45 \%$ of men had two or more sex partners (Kishamawe et al 2006). Vissers et al (2008) report that in their sample, $67.8 \%$ of coresidents and $86.6 \%$ of couples living apart had unprotected sex at their last extramarital sex act. However, the data on sexual behaviour presented in both studies varied significantly by gender, with men reporting far higher levels of extra-marital sexual behaviour then women (see Nnko et al 2004). HIV prevalence in the study site at the time of the fieldwork was $6 \%$ (Kanjala et al 2014), similar to the national average of 5.9\% reported in the Tanzanian HIV/AIDS and Malaria Indicator Survey 2011-12 (TACAIDS 2013).

The main component of the fieldwork was comprised of three interlinked phases. The initial exploratory phase aimed to understand more about the reasons for participants leaving the study site, and also to select the mobile groups to be studied in subsequent stages of the research. Four focus groups, each with 12 people in, were conducted in the rural and urban areas for men and women separately, with participants invited through local community gatekeepers. No demographic information was captured at this stage, but participants had been recruited to reflect a range of ages and backgrounds. The mobile groups identified as the most important, and which were selected for inclusion in the study were mobile farmers who farmed land outside the ward, and businesspeople such as maize traders and dagaa ${ }^{1}$ sellers.

In phase two, mobility and risk were explored at a general level by mapping out each selected mobility process in four focus groups comprised of a sample of each mobile group and in the third phase, a sub-sample of each focus group were interviewed to document personal experiences of engaging in the general processes mapped in the previous phase. Sexual

\footnotetext{
${ }^{1}$ Small dried fish
} 
behaviour, at a general and individual level, was explored in both the focus groups and interviews. The design of the focus groups and in-depth interviews in phases two and three were informed by theoretical and methodological work in which migration is conceptualised as a socio-economic process (Boyd, 1989; Fawcett \& Arnold, 1987; Massey et al., 1993). The process-mapping exercise produced stylised diagrams that documented key sequential characteristics of each process such as the reasons for moving, patterns of moving, what mobile individuals did while away, and what they did when they returned home. An additional phase comprised of two focus groups to discuss issues relating to transactional sex was added towards the end of the project. Table 1 details the number of participants in each phase of the study. Concurrent activities included informal interviews, discussions with key informants and the local research community, and additional secondary research.

\section{[Place Table 1 about here.]}

The findings reported in this article focus on the mobile farmers and maize traders, though the analysis is informed by the other research activities. The 12 mobile farmers were recruited for the focus group through local contacts such as DHS enumerators and community leaders. Of these 12 farmers, five were interviewed in the next stage, along with two female mobile farmers who we encountered during the recruitment process. The maize traders were recruited at the maize-selling area located in the middle of the urban centre and the weekly local market. In total, seven male maize traders and three female maize traders were interviewed, though only three of the male maize traders participated in the focus group. This number of maize traders represented a high proportion of active maize traders living in the study site. Whilst the absolute number of participants across all phases of the fieldwork was relatively small compared to quantitative surveys and other qualitative work, this approach enabled some very specific mobile groups to be studied in-depth over repeated iterations.

The data collection period ran from March to September 2011. Research activities were conducted by same sex research assistants ${ }^{2}$ fluent in Swahili and Sukuma, the two main local languages. The author observed the focus groups in phase one, but was not present for the rest of the research activities due to the sensitive issues covered. The research assistants undertook a training programme which included an introduction to the key themes of the project and the different qualitative techniques to be used, and practising and piloting all

\footnotetext{
${ }^{2}$ For a full discussion on the role of research assistants, see Deane \& Stevano 2016
} 
research tools before use in the field. Informed consent was gained from all participants, and research activities were recorded where appropriate ${ }^{3}$ and later transcribed and translated. A structured debrief with the research assistants was conducted after every research activity to discuss emerging themes and the research process, with notes from these debriefs triangulated with the translated transcripts, providing a rich dataset.

The data was analysed in a number of ways specific to each of phases. In phase one, the mobile groups to be studied were selected by counting the frequency they were ranked in the top six reasons for moving in each focus group. The second phase produced a series of detailed process maps and translated transcripts, which were analysed along with the in-depth interview transcripts and debrief notes using Nvivo v9. However, emerging themes had been discussed throughout the project, blurring the lines between data collection and analysis (Schiellerup, 2008). Ethical approval was granted by the ethics committees of SOAS, the London School of Hygiene and Tropical Medicine, and the Medical Research Coordinating Committee of Tanzania.

\section{Results}

Demographic characteristics of mobile farmers and maize traders

The mobile farmers interviewed were all aged between 30 and 40, with one male farmer aged 57. All reported that they were married and had between 2-7 children. The mobile farmers were primarily own account farmers as opposed to migrant farm workers, owning between 15 acres of land in the study site, and supplementing their income with other economic activities including carpentry, construction work, photography, and brick making. They all reported hiring casual labour in the destination areas that they visited to help them with their farming activities, and had kinship networks that were able to provide access to additional land in these destination areas.

The maize traders were all in their thirties apart from one female trader who was 23, and two male traders who were 43 and 53 respectively. Male maize traders reported purchasing between 50 and 200 sacks of maize on buying trips in comparison to 20 sacks that female maize traders reported purchasing. Many of the traders reported accumulating assets such as bicycles, a milling machine, a motorcycle, plots of land, houses, farmland and a sewing machine. Reflecting the broader migration literature (de Haas, 2005) these economic

\footnotetext{
${ }^{3}$ Some sections of the focus groups in phase one that involved the participants working in pairs or smaller groups were not recorded
} 
characteristics suggest that the participants from both these mobile groups were not amongst the poorest of the population, though precise income measurements were not taken as part of this study.

\section{Patterns and conditions of moving}

One important objective stressed above was to incorporate migration and mobility as a process, and also to understand how engaging in these processes, and the associated lifestyles this brings, influences HIV risk. Therefore, the processes are presented first, with the data on sexual behaviour following. The general processes discussed in this section are in reality extremely heterogeneous, and so what follows are to some extent stylised accounts, with a focus on the key factors that are related to sexual behaviour.

Farmers reported that the precise pattern of movement between the study site and destination areas is influenced by a range of factors, including distance from the ward, the cost of travelling, the nature and duration of livelihood activities, and other household issues, such as how long the household can survive without the head of the household. With these variations in mind, a typical growing season involves three visits, one each for land preparation and planting, weeding and checking on general progress, and harvesting. The pattern of movement, with farmers travelling to one destination, multiple times per growing season, with trips lasting around one month or more, and potentially repeating this over a number of years, while mediated by a range of other factors, is strongly influenced by the demands of cultivating land away from the ward, and specifically tasks that demand their labour.

Maize traders reported contrasting patterns of movement, typically between one and two buying trips per month often to different destinations, with the trips lasting anywhere from a few days to a few weeks. The frequency of buying trips is determined by how quickly maize from the previous buying trip is sold, as most maize traders are reliant on selling their last load to refresh their capital. The length of time spent away is determined by the distance they have travelled, and also by how quickly the buying process is completed. The main issues that extend the time spent away are that the maize is not available when they arrive, problems with negotiating and buying the maize from local collectors and middlemen, and waiting for transport. As with the farmers above, the demands of the economic activity exert a strong influence over the patterns of movement, though in this case this is characterised by multiple trips to different destinations, and shorter periods of time spent away. 
In terms of the reasons for moving, and also the practicalities of living away, farmers reported that they farmed land away from the ward because they were looking for cheaper and more productive land to cultivate, as land in the study site is expensive to rent or buy and in short supply, with farmers noting that land prices have increased rapidly due to the recent land reform act and pending formalisation of land titling (Shivji, 1998), which in turn had stimulated land speculation by urban elites. Further, the land is perceived as unproductive due to continued cultivation for a long period of time. Typically farmers reported accessing land away through kinship or community networks, for example through a father-in-law, a friend, or parents. These existing networks influence where farmers decide to actually go. Accessing land through these networks also has implications for where farmers live and stay, which is with family or friends in rural villages near their farms, and has further implications for the nature of the relationship that mobile farmers have with the local community, in which they are often already known or have connections through local inhabitants.

Where maize traders go is predominantly determined by information they receive on price and availability of maize, and whether this will enable them to make a profit when accounting for the costs of the buying trip and the local price in and around Mwanza city. The areas that they travel to are also shaped by the structure of regional maize production, and longestablished trading routes (Chemonics International Inc., 2010; Santorum \& Tabaijuka, 1992), as Mwanza has long been a maize-deficit region. Typically, they are businessmen travelling to places where they are not known, unless they have friends, relatives, or contacts that they have made in regular destinations. As a result of this, traders reported staying in a guesti (guesthouse) in local urban centres, and ate in the evenings at local hotels and bars in the urban centres. As with the farmers, the factors that influence where maize traders go also shape where they live and stay, and the relationship that they have with the local community.

These brief descriptions of the key elements of each process highlight the different patterns and conditions of moving, which are shaped by the different requirements of each economic activity, and sets the platform for examining how the patterns and conditions of moving, and the relationships that mobile individuals have with the destination area influence their sexual behaviour.

\section{Mobility and sexual behaviour}

Before presenting the key themes, it is worth noting that not every mobile individual in this study reported having sex while they were away, and also that both farmers and maize traders 
understood that sexual behaviour is to some extent influenced by a range of other factors, including individual motivations. Six out of seven male maize traders and four out of five male mobile farmers and reported having partners whilst away, although in line with the previous quantitative work in this study site discussed above, none of the female participants reported having extra-marital partners. Both mobile groups reported reasons for having sex while away that echo the 'being away' narrative and male sexual needs:

"As I tried to say that, it is very difficult for us youth, to control oneself that I should not do this until...that is not easy. I remember it was a very long time; I spent about two months, Now... I failed to control myself that aa...I can't take it any longer, I really got a woman" (male farmer)

"Something convinced me, if you are virile man, you must have a woman. Even if you try hard not to do it, if you are a virile man [laughter] you must do it, you have to find even one" (male maize trader)

Beyond this, a number of themes related to the specific nature of each livelihood emerged. The first theme was that farmer and maize traders reported different types of sexual relationships and partners. Farmers typically reported that they had one regular partner in the destination area, rather than multiple sexual partners, and that they went back to this partner each year/trip away:

R: "To be honest, in those four months, I had someone there, especially in the second year, I just got that one. She is there at any time I go there, is also a good farmer" ... Interviewer: 'Therefore it was in your second year, the first year just passed...'

R: "Was just passed free"

Interviewer: 'What about the third and the fourth year?'

R: "It is the same woman" (male farmer)

This is perhaps to be expected, as farmers have time to build relationships in the destination area when they travel to the same place several times a year, over a number of subsequent years. In contrast, maize traders reported having sex with a number of one-off partners across different geographical locations, reflecting the different form of mobility, in which they go to multiple destinations but only stay a short time:

"I can say that, for these two in this year I have made love with them, I engaged in love affairs one time with one of the women and two times with another one, In March....in April to June" (male maize trader)

The nature of these extra marital relationships has important implications for condom use. For farmers, two themes emerged. Firstly, one farmer reported that he did not use condoms 
with the partner that he had whilst he was away after the first year of this relationship, as he trusted that she was 'safe':

"I used protection; I used protection for one year. Later things turned upside down, now one year later, I found it nonsense. That friend of mine told me that; " this one is good, she is also spending her time doing activities". I trusted that she is ok/ safe" (male farmer)

Whilst this in part reflects misinformation around how one can tell if someone is likely to be infected or not, it also highlights other issues around trust and condom use with regular partners, echoing findings in other studies that suggest condom use is more likely to be used with casual or one-off partners rather than regular partners (Waithaka \& Bessinger, 2001). Secondly, another farmer noted that the practicalities of accessing condoms, in a situation in which he was attempting to avoid drawing attention to his relationship and hence having sex in the fields outside the village, were a factor in him having unsafe sex:

"At the first time; we went to a guesthouse, yes, we took a breather there and in doing sexual intercourse I used a condom... Fortunately we were not living far from each other. I didn't know at which village she was living, thus we used to see/meet each other, as we were doing it secretly. For us to meet, we have to go to... the center, we realised that...it doesn't bring a good picture, thus we should do everything here [in the village, not the urban centre] ... Thus we used to do unsafe sex, we were not using condom" (male farmer)

This farmer was dealing with the added complexity of staying in the village with his fatherin-law, whom he was accessing land through, emphasising the influence perceived social and community constraints on his sexual behaviour. However, in contrast to some accounts in which these social constraints are viewed as protective (Caldwell et al., 1997), the creative ways in which some mobile individuals circumvent these constraints is a contributing factor to the lack of condom use.

In contrast, the maize traders who had engaged in sexual interactions whilst away reported that they did use condoms:

(Interviewer: 'Perhaps what convinced you to decide to use protection?') Respondent: "It is just because I just met her there and that I do not know her past...how is her life in that village, whether she ever got married or not in her young age before I met her, or if she ever go to other places out of her ward" (male maize trader) 
Whilst responses such as these must be carefully interpreted and may represent socially acceptable answers, maize traders generally have better access to condoms, and consequently the opportunity to use them due to the fact that their accommodation on buying trips is typically located in local urban centres, where condoms are often available. Further, as they are generally staying in places where they are not well known, purchasing condoms is less of a risk in terms of spouses or other family members finding out. Conversely, the specific contexts that farmers move into may make buying and using condoms more difficult.

A third theme was related to how mobile individuals access local sexual networks, and indeed whom they have sex with, and emphasises how engaging in specific livelihood activities puts different individuals into different risk contexts. For example, as most maize traders stayed in a guesti in the local urban centre, and went to a local restaurant or bar for something to eat and drink in the evenings, they identified this as an environment in which they would be likely meet women, and are also places where prostitutes or women who were looking to engage in transactional sex (see below) can be found:

"Such things do exist, do you see, they are mostly available at the center. Yes, around centers is where those temptations are found, however when you are there in the villages such things are very rare ... they are not very much entertained there" (male maize trader)

"And there are many women there at Buselesele, mm, even those doing prostitution are many too, yes, that is why I am saying that, it depends on how committed/strong you are" (male maize trader)

In contrast, male farmers reported that the women they had sex with were other farmers from the villages that they were staying in, accessing local sexual networks, either through having potential sexual partners recommended by a friend, or through staying in communities in which they were already known. Whilst we do not know exactly who farmers and maize traders are having sex with, this emphasises that who mobile groups have sex with is strongly influenced by the different ways that they meet potential partners. Who mobile groups have sex with, and the likelihood of them being infected, is clearly central in determining whether a mobile individual gets infected or not, highlighting the need to account for background prevalence rates, which can vary hugely over short geographical places, and the sexual history of potential partners.

There are also some specific influences on the risk behaviours of maize traders that are related to the timings of their buying activities. With some parallels with Stillwaggon's 
(2006) analysis of sexual behaviour at border crossings (Stillwaggon, 2006), maize traders reported engaging in sexual activity when they were waiting for transport back home:

"Temptations are necessary to be there, for example when buying these products, as you will have finished purchasing activities, You will have staying doing nothing as you have finished buying, You have satisfied purchasing / the products are sufficient, temptations are necessary, because you are through with other duties" (male maize trader)

"I didn't have a partner, because even the chance, I did not have it, because I am saying so depending on the place, that is, there, it was the place we used to go, but it was not protected to the extent that you will make sure you buy the crops as quick as you can so that you can go back home" (male maize trader)

This is one of the points in the process when they report having sex, whilst conversely it was reported that when business activities are concluded swiftly, they have little time to think about or engage in sex. The difficulties in arranging transport are in part a result of the difficulties of the business itself. Maize traders make profits by exploiting price differentials between geographical areas, and so information about price and availability is key. Further, the negotiation process with local village collectors does not always go smoothly, so arranging transport is also difficult if traders do not know the exact prices or availability of maize until they arrive somewhere, or their a priori expectations about prices are not met.

Of course, not all mobile individuals reported having sex while away. One mobile farmer who travelled with his wife reported not engaging in any extra marital sex as he did not have the opportunity too:

"Perhaps for...mostly is that, maybe because I travelled with my wife, with my partner, I had no desire that, I am not so desperate to have sex [Laughter]. I think it is what made me return without doing it" (male farmer)

This was due to the fact that this farmer's mother-in-law lived with them at home, and so could look after the children while he travelled with his wife. However, all other farmers reported travelling on their own, with the partner staying at home to look after the children for schooling purposes, in some cases alternating with their partners.

The experience of the small number of female participants in the study was markedly different in comparison to their male counterparts. One female farmer reported that whilst she did attract attention, she wanted to maintain her status and not offend her in-laws whom she was staying with 
"There are many people adoring you but because you want to maintain your status, Yes, it is not good to do that thing while you are at foreign land. Moreover, it is not good there at in law's home land" (female farmer)

This contrasts with the male farmer above who did not find that staying with his in-laws prevented him from having a relationship whilst away. Female maize traders reported a degree of harassment whilst they were away, noting that they were repeatedly propositioned, and that to some extent, they were viewed as prestigious potential partners as they were from close to Mwanza city:

"There people of that kind, he can tell you that, "I love you madam", but we are scared because people nowadays are not faithful. You tell him that; guy, I am here just for my business, I am not here for those things. Thus you will have left him, another one will also come to you telling you the same thing and you will tell him different things (Female maize trader)

(Interviewer: 'Is it a prestige to have a woman from Mwanza?')

'Ee'

(Interviewer: 'They are competing to see who will get a woman from Mwanza')

"Ee [laughter], who will win a woman from Mwanza (female maize trader)

Although the female maize traders did not report succumbing to this pressure, it is questionable whether all women put in this position will have the power or protection to reject unwelcome advances, especially when they are staying away from home in areas about which they expressed doubts over their own personal security.

\section{Reconsidering the role of mobility: transactional sexual norms}

Alongside themes that relate sexual behaviour to mobility, participants also related the reasons for their engagement in sexual interactions to sexual norms around sex and exchange (Wamoyi, Fenwick, Urassa, Zaba, \& Stones, 2011; Wamoyi, Wight, Plummer, Mshana, \& Ross, 2010). For example, one farmer reported that he had sex with a hired labourer:

"There at our agricultural activates, especially to those we are employing, those casual labourers, because you can't employ men only there must be women. Now if you employ women there must be temptations, the women will seduce you, so that can pay them more, you have agreed, she wants you to make love with her so that you can pay her more through making sex with her" (male farmer)

In this case the farmer reported that the female labourer (successfully) tried to seduce him so that he would increase her wages. The maize traders also emphasised that there was an 
expectation that money was exchanged when having sex with someone, echoing sexual norms around transactional sex:

"Therefore, when you have... little amount of money...you can look for a friend for...but if you have run out completely... It is impossible ... in today's situation, I mean...it have been a business to women, It is impossible, I mean, even if you try to convince her, it is...they do it for money, I mean it have already been a business. You can try your best to convince her, but at the end of the day (she) will demand money." (male maize trader)

(Interviewer: 'Ok ...perhaps have you ever made love with a woman in exchange with maize or cassava, have this ever happen to you?') "There is no such a thing, don't underestimate us; we do respect our business because if she needs money for expenditure, you will give her". (male maize trader)

The issue of sex for exchange was also reflected in the fact that maize traders reported that they were targeted by local women, as once their purpose was known, women realised that they had money with them (on their buying trips), and so they were a potential source of money and hence desirable sexual partners:

"Yes, as you know in those years, as a business person you can just find yourself seduced by a woman" (male maize trader)

"At the places you use to go, you can go at night clubs/entertainment places, somebody may come while resting telling you that; "can you buy me a drink" and because they know you that you use to go at their places to buy maize" (male maize trader)

"Because every woman sees you think that, it is her opportunity to get money." (male maize trader)

This is not to suggest that maize traders are 'helpless' targets of local women, but echoes the case studies of truck drivers that suggests they are often viewed as desirable sexual partners (Kamwanga et al., 2006). Further, other study participants noted that men used these opportunities in a coercive manner to extract sex, highlighting that these transactional interactions will occur with varying degrees of male and female agency (Deane and Wamoyi, 2015). These examples emphasise that income differentials between maize traders, who have money available to use for purchasing maize, and potential sexual partners in destination areas, can influence sexual interactions. Further, these sexual interactions engaged in by mobile groups are influenced by their roles as employers or businessmen, linked to the relative inequalities in terms of gender and economic power, and rooted in broader social relations. 


\section{Discussion}

The results presented here illustrate that the requirements of engaging in specific economic activities exert a strong influence over the patterns and conditions of moving, such as how many different destinations mobile individuals go to, the frequency of visits and the length of time spent away. Further, the different reasons that draw mobile individuals to specific destinations, such as community networks or price and availability of maize, influences where mobile individuals stay, where they sleep and eat, and thus frame the nature of the relationship they have with the local community Importantly, the patterns and conditions of moving can influence the nature of sexual relationships that mobile individuals have whilst away, and also how mobile individuals access local sexual networks, which in turn has implications for condom use. The analysis presented here is not to be interpreted as being overly deterministic, as it is clear that not all maize traders will only have one-off partners, or all farmers will have more permanent partners in destination areas. The primary aim is to illustrate how a range of different elements conceived of at different levels of analysis combine and interact to influence sexual behaviours linked with enhanced HIV transmission

These insights have been enabled by the materialist approach employed which enables the role of structural factors to be fully articulated, with broader systemic processes influencing the context into which mobile individuals move, as well as sexual behaviours. Whilst there is evidence to support the standard 'being away' narrative, we find that the relationship is more complex, with attention diverted away from individual decisions towards the role of broader structural, and potentially unacknowledged, forces. The analysis also emphasises that a higher number of sexual partners may not always equate to higher risk of HIV infection if condoms are more likely to be used with one-off partners, highlighting that the nature of the sexual relationships that mobile individuals have, rather than the quantity of partners, will influence condom use (Slaymaker, 2004).

Our findings highlight a number of important factors that could be included in future, more nuanced, statistical work, including why people move, where they go, patterns of movement, specific economic activities that are engaged in and related to mobility, where they stay whilst they are away, and their reasons for having sex. Whilst these may appear obvious factors to include, statistical work continues to focus predominantly on the correlation between sexual behaviours and HIV prevalence and abstract categories of mobility (McGrath, et al., 2015; Palk and Blower 2015). 
We also find that the risk behaviours of mobile individuals are influenced by sexual norms and practices around sex and exchange, identified as an important driver of extra-marital sex by other studies conducted in Tanzania (Wamoyi et al., 2011; Wamoyi et al., 2010), with transactional sex viewed as particularly 'risky' (Dunkle et al., 2004). These transactional sexual interactions reflect unequal gender and economic relations, and provide an explanation of the underlying determinants of the risk that mobile individuals face. In this case, engaging in mobility may exacerbate gendered and economic inequalities in cases when mobile traders and farmers travel to more isolated and poorer areas, making the relative influences of mobility and sexual norms overlapping and difficult to disentangle. This finding is reflected in recent work, though with a focus on women's mobility, in which transactional sex and mobility are intimately related (Camlin, Kwena, Dworkin, Cohen, \& Bukusi, 2014). This suggests that 'mobility' is not necessarily the most important element of risk that mobile groups face, and that understanding the role of gender relations and norms remains central to the analysis.

The results from this research project have implications for future HIV prevention efforts. Firstly, policy suggestions that aim to encourage couples to move together may not be applicable to occupations such as maize trading which involve multiple short-term trips that do not lend themselves to partners moving together. This may be more applicable to farming, as there is more potential for the household to move on a permanent basis, but whether this happens or not will depend on the degree to which the family is settled in the study site, and other concerns such as access to services and Mwanza city. Further, it is unclear precisely what kind of policies could be used to encourage resettlement, and whether this is even desirable in relation to broader developmental goals (UNDP, 2009). This highlights the need for more research to enable policy makers to root policy in an understanding of the ways that mobile individuals experience risk.

A related implication is that different mobile groups may need different targeted intervention programmes. For farmers, our results highlight the importance of encouraging condom use with longer term sexual partners. This is no easy task, as it involves a number of issues that are related to education and the dynamics of relationships which involve trust and intimacy (Bujra 2000). Our analysis also points towards an approach to policy making first forwarded by Stillwaggon (2006), in which delays at border crossings were identified as one of the situations in which truck drivers were most likely to drink alcohol and engage in sexual 
activity $^{4}$. Stillwaggon suggests that prevention efforts could focus on speeding up customs clearance, and hence reduce the amount of time that truck drivers wait at borders, rather than on more traditional interventions such as condom distribution and promotion. Further, reducing waiting times would also have economic benefits for those transporting the goods in terms of lower transport costs and lower losses of perishable primary goods. This policy approach would seem to have both public health and economic benefits (Deane et al., 2013; Stillwaggon, 2006). When applied to the case of the maize trading process, we can identify the inefficiencies of the transportation of maize through the value chain as a potential factor that contributes to the dynamics of transmission, as maize traders report having sex whilst away when they have finished their buying activities and are waiting for transport. Potential interventions may focus on the use of mobile phones to transfer money and conduct deals without the need for travel, better flows of information about pricing and availability, legal systems to uphold purchasing agreements and closer integration of transport operators and those working in these value chains. This demonstrates the value of mapping out forms of mobility to understand more about the points in the process when risky sexual behaviour may occur.

This study has emphasised the complexity of the relationship between mobility and HIV, and has provided a range of insights regarding the influences over the nature of relationships that mobile individuals have whilst they are away, and some of the structural factors, such as gender relations and transactional sexual norms, which shape risk, and which overlap with mobility. These insights have been made possible through the use of a materialist approach which focuses on how engaging in specific livelihood activities contributes to HIV risk. Future work must continue to engage with the role of structural drivers and to incorporate a gendered perspective to fully address HIV risk and mobility.

\section{Acknowledgments}

This PhD project was supervised by Dr Deborah Johnston (SOAS) and Dr Justin Parkhurst (LSHTM). Fieldwork was supported by John Changalucha and Ray Nsigaye of the National Institute of Medical Research, Tanzania, Mwanza Branch. Research activities were conducted by Lucas Boniface, Penina Samwell and Grace Bulugu, with assistance from Joyce Chuwa, Mathias Shimo and Mpyanjo Chagu. This paper has benefitted from comments from Jim Todd and Tanvi Rai on earlier drafts, and from three anonymous reviewers.

\footnotetext{
${ }^{4}$ Though this was largely ignored by policy makers who implemented a standard education and condom promotion scheme, see Stillwaggon, E. (2006).
} 


\section{Funding}

This project was supported by Bloomsbury Colleges and the London International Development Centre

\section{Disclosure Statement}

The author has not derived any financial interests or benefits arising from the direct applications of this research

\section{References}

Ager, A., Stark, L., \& Potts, A. (2010). Participative Ranking Methodology: A Breif Guide Auerbach, J., Parkhurst, J., \& Caceres, C. (2011). Addressing social drivers of HIV/AIDS for the long-term response: Conceptual and methodological considerations. Global Public Health, 6(S1), S293-S309

Baltazar, C.S, R. Horth, C. Inguane, I. Sathane, F. Cesar, H. Ricardo, C. Botao, A. Augusto, L. Cooley, B. Cummings, H. Raymond \& P. Young (2015), HIV Prevalence and Risk Behaviors Among Mozambicans Working in South African Mines, AIDS Behav, 19(S1), 59-67

Bernstein, H. (2010). Class Dynamics of Agrarian Change. Halifax and Winnipeg: Fernwood Publishing

Boerma, J. T., Urassa, M., Senkoro, K., Klokke, A., \& Ngweshemi, J. Z. (1999). Spread of HIV infection in a rural area of Tanzania. AIDS, 13(10), 1233-1240

Boyd, M. (1989). Family and Personal Networks in International Migration: Recent Developments and New Agendas. International Migration Review, 23(3), 638-670

Bujra, J (2000), Risk and Trust: Unsafe Sex, Gender and AIDS in Tanzania, in P. Caplan (ed), Risk Revisited, Pluto Press:London

Caldwell, J. C., Anarfi, J. K., \& Caldwell, P. (1997). Mobilty, Migration, Sex, STD's and AIDS: An Essay on Sub-Saharan Africa with Other Parallels. In G. Herdt (Ed.), Sexual Cultures and Migration in the Era of AIDS. Oxford: OUP

Camlin, C. S., Kwena, Z. A., Dworkin, S. L., Cohen, C. R., \& Bukusi, E. A. (2014). "She mixes her business": HIV transmission and acquisition risks among female migrants in western Kenya. Social Science \& Medicine, 102(0), 146-156

Campbell, C. (1997). Migrancy, masculine identities and AIDS: The psychosocial context of HIV transmission on the South African Gold Mines. Soc Sci Med, 45(2), 273-281

Campbell, C. (2003). Letting Them Die. Oxford: James Currey

Campbell, C., \& Williams, B. (1999). Beyond the biomedical and behavioural: towards an integrated approach to HIV prevention in the Southern African mining industry. Social Science \& Medicine, 48(11), 1625-1639

Carswell, J. W., Lloyd, G., \& Howells, J. (1989). Prevalence of HIV-1 in east African lorry drivers. AIDS, 3(11), 759-761

Chemonics International Inc. (2010). Staple Food Value Chain Analysis: Country Report Tanzania

Coffee, M., Lurie, M. N., \& Garnett, G. P. (2007). Modelling the impact of migration on the HIV epidemic in South Africa. AIDS, 21(3), 343-350

Coffee, M. P., Garnett, G. P., Mlilo, M., Voeten, H. A., Chandiwana, S., \& Gregson, S. (2005). Patterns of movement and risk of HIV infection in rural Zimbabwe. J Infect Dis, 191 Suppl 1, S159-167 
De Haas, H. (2005). International Migration, Remittances and Development: myths and facts, Third World Quarterly, 26(8): 1269-1284

Deane, K \& S. Stevano (2016), Towards a political economy of the use of research assistants: reflections from fieldwork in Tanzania and Mozambique, Qualitative Research, 16(2), 213-228

Deane, K \& J. Wamoyi(2015), Revisiting the economics of transactional sex; Evidence from Tanzania, Review of African Political Economy. 42(145), pp. 437-454

Deane, K, D. Johnston \& J. Parkhurst (2013), Migration as tool in development policy: cause for concern?, The Journal of Development Studies. 49(6), 759-771

Deane, K, J. Parkhurst \& D. Johnston(2010, Linking Migration, Mobility and HIV, Trop Med Int Health, 15(12), 1458-1463

Douglas, E. (2000). Putting on the Brakes - Preventing HIV Transmission along truck routes. Washington: C. f. H. E. a. R. The Synergy Project and the University of Washington

Dunkle, K. L., Jewkes, R. K., Brown, H. C., Gray, G. E., McIntyre, J. A., \& Harlow, S. D. (2004). Transactional sex among women in Soweto, South Africa: prevalence, risk factors and association with HIV infection. Soc Sci Med, 59, 1581-1592

Fawcett, J. T., \& Arnold, F. (1987). The Role of Surveys in the Study of International Migration: An Appraisal. International Migration Review, 21(4), 1523-1540

Gupta, G. R., Parkhurst, J. O., Ogden, J. A., Aggleton, P., \& Mahal, A. (2008). Structural approaches to HIV prevention. The Lancet, 372(9640), 764-775

Hahn, R. A. (1991). What Should Behaviorual Scientists Be Doing About AIDS? Soc Sci Med, 33(1), 1-3

Iliffe, J. (2006). The African AIDS Epidemic: A History. Oxford: James Currey

Kamwanga, J., Simbaya, J., \& Luhana, C. (2006). Corridors of Hope in Southern Africa: HIV prevention needs and opportunities in Four Border Towns. F. H. International

Kanjala, C, D. Michael, J.Todd, E. Slaymaker, C. Calvert, R. Isingo, A. Wringe, B. Zaba and M. Urassa (2014), Using HIV-attributable mortality to assess the impact of antiretroviral therapy on adult mortality in rural Tanzania, Global Health Action, Vol.7, 21865

Khan, M. R., Patnaik, P., Brown, L., Nagot, N., Salouka, S., \& Weir, S. S. (2008). Mobility and HIV-related sexual behavior in Burkina Faso. AIDS Behav, 12(2), 202-212

Kishamawe, C., Vissers, D. C., Urassa, M., Isingo, R., Mwaluko, G., Borsboom, G. J. (2006). Mobility and HIV in Tanzanian couples: both mobile persons and their partners show increased risk. AIDS, 20(4), 601-608

Lagarde, E., Schim van der Loeff, M., Enel, C., Holmgren, B., Dray-Spira, R., Pison, G. (2003). Mobility and the spread of human immunodeficiency virus into rural areas of West Africa. Int J Epidemiol, 32(5), 744-752

Lurie, M. N., Williams, B. G., Zuma, K., Mkaya-Mwamburi, D., Garnett, G., Sturm, A. W. (2003a). The impact of migration on HIV-1 transmission in South Africa: a study of migrant and nonmigrant men and their partners. Sex Transm Dis, 30(2), 149-156

Lurie, M. N., Williams, B. G., Zuma, K., Mkaya-Mwamburi, D., Garnett, G. P., Sweat, M. D. (2003). Who infects whom? HIV-1 concordance and discordance among migrant and non-migrant couples in South Africa. AIDS, 17(15), 2245-2252

Lydie, N., Robinson, N. J., Ferry, B., Akam, E., De Loenzien, M., \& Abega, S. (2004). Mobility, sexual behavior, and HIV infection in an urban population in Cameroon. $J$ Acquir Immune Defic Syndr, 35(1), 67-74

Massey, D. S., Arango, J., Hugo, G., Kouaouci, A., Pellegrino, A., \& Taylor, J. E. (1993). Theories of International Migration: A Review and Appraisal. Population and Development Review, 19(3), 431-466 
Mmbaga, E. J., Leyna, G. H., Hussain, A., Mnyika, K. S., Sam, N. E., \& Klepp, K. I. (2008). The role of in-migrants in the increasing rural HIV-1 epidemic: results from a village population survey in the Kilimanjaro region of Tanzania. Int J Infect Dis, 12(5), 519525

McGrath, N, J. Eaton, M-L Newell and V. Hosegood (2015), Migration, sexual behaviour, and HIV risk: a general population cohort in rural South Africa, The Lancet HIV, 2(6), e252-e259

Nnko, S, J.T. Boerma, M. Urassa, G. Mwaluko and B. Zaba (2004), Secretive females or swaggering males?: An assessment of the quality of sexual partnership reporting in rural Tanzania, Soc Sci Med 59 (1), 299-310

Palk, L and S. Blower (2015), Brief Report: Mobility and Circular Migration in Lesotho: Implications for Transmission, Treatment, and Control of a Severe HIV Epidemic, JAIDS, 68(5), 604-608

Santorum, A., \& Tabaijuka, A. (1992). Trading responses to food market liberalization in Tanzania. Food Policy, 17(6), 431-442

Schuyler, A, Z. Edelstein, S. Mathur, J. Sekasanvu, F. Nalugoda, R. Gray, M. Wawer, D.Serwadda \& J. Santelli (2015), Mobility among youth in Rakai, Uganda: Trends, characteristics, and associations with behavioural risk factors for HIV, Global Public Health, DOI:10.1080/17441692.2015.1074715

Schiellerup, P. (2008). Stop making sense: the trials and tribulations of qualitative data analysis. Area, 40(2), 163-171

Shivji, I. (1998). Not Yet Democracy: reforming land tenure in Tanzania. Dar Es Salaam: International Institute for Environment and Development and University of Dar Es Salaam

Slaymaker, E. (2004). A critique of international indicators of sexual risk behaviour. Sexually Transmitted Infections, 80(suppl 2), ii13-ii21

Stillwaggon, E. (2006). Reducing Environmental Risk to Prevent HIV Transmission in subSaharan Africa. Africa Policy Journal, Spring 2006 Vol.1, 21

Sumartojo, E., Doll, L., Holtgrave, D., Gayle, H., \& Merson, M. (2000). Enriching the mix: incorporating structural factors into HIV prevention. AIDS, 14 Suppl 1, S1-2

TACAIDS (2013), Tanzania HIV/AIDS and Malaria Indicator Survey 2011-12, Dar Es Salaam: TACAIDS, ZAC, NBS, OCGS, and ICF International

Tanser, F., Lesueur, D., Solarsh, G., \& Wilkinson, D. (2000). HIV heterogeneity and proximity of homestead to roads in rural South Africa: an exploration using a geographical information system. Trop Med Int Health, 5(1), 40-46

Thomas, F., Haour-Knipe, M., \& Aggleton, P. (Eds.). (2010). Mobility, Sexuality and AIDS. Abingdon: Routledge

UNAIDS. (2010). Combination HIV Prevention: Tailoring and Coordinating Biomedical, Behavioural and Structural Strategies to Reduce New HIV Infections. Geneva. Retrieved from UNAIDS Discussion Paper

UNDP. (2009). Overcoming Barriers: Human Mobility and Development. New York: P. Macmillan. Retrieved from Human Development Report.

Vissers, D. C., Voeten, H. A., Urassa, M., Isingo, R., Ndege, M., Kumogola, Y. (2008). Separation of spouses due to travel and living apart raises HIV risk in Tanzanian couples. Sex Transm Dis, 35(8), 714-720

Waithaka, M., \& Bessinger, R. (2001). Sexual Behavior and Condom Use in the Context of HIV Prevention in Kenya 
Wamoyi, J., Fenwick, A., Urassa, M., Zaba, B., \& Stones, W. (2011). "Women's Bodies are Shops"; Beliefs About Transactional Sex and Implications for Understanding Gender Power and HIV Prevention in Tanzania. Arch Sex Behav, 40(1), 5-15

Wamoyi, J., Wight, D., Plummer, M. L., Mshana, G. H., \& Ross, D. (2010). Transactional sex amongst young people in rural northern Tanzania: an ethnography of young women's motivations and negotiation. Reproductive Health, 7(2)

Weine, S. M., \& Kashuba, A. B. (2012). Labor Migration and HIV Risk: A Systematic Review of the Literature. AIDS Behav, 16(6), 1605-1621

Table 1. Summary of research activities and numbers of participants.

\begin{tabular}{|c|c|c|}
\hline Phase & Activity & $\begin{array}{l}\text { No of } \\
\text { Participants }\end{array}$ \\
\hline \multirow[t]{4}{*}{ One } & Urban/Female Focus Group & 12 \\
\hline & Urban/Male Focus Group & 12 \\
\hline & Rural/Female Focus Group & 12 \\
\hline & Rural/Male Focus Group & 12 \\
\hline \multirow[t]{4}{*}{ Two } & Mobile Farmers Focus Group & 12 \\
\hline & Maize Traders Focus Group & 3 \\
\hline & Dagaa Sellers (male) Focus Group & 12 \\
\hline & $\begin{array}{l}\text { Dagaa Sellers (female) Focus } \\
\text { Group }\end{array}$ & 7 \\
\hline \multirow[t]{4}{*}{ Three } & Mobile Farmer Interviews & 7 \\
\hline & Maize Trader Interviews & 10 \\
\hline & Dagaa sellers (male) interviews & 5 \\
\hline & Dagaa sellers (female) interviews & 5 \\
\hline \multirow[t]{2}{*}{ Four } & Focus Group (male) & 12 \\
\hline & Focus Group (female) & 12 \\
\hline
\end{tabular}

